\title{
Human Chromosome 17 NotI Linking Clones and Their Use in Long-Range Restriction Mapping of the Miller-Dieker Chromosome Region (MDCR) in 17p13.3
}

\author{
Susan A. Ledbetter, * Margaret R. Wallace, † Francis S. Collins, † and David H. Ledbetter, ${ }^{* 1}$ \\ *Institute for Molecular Genetics, Baylor College of Medicine, Houston, Texas 77030; and †Howard Hughes Medical Institute \\ and Departments of Internal Medicine and Human Genetics, University of Michigan, Ann Arbor, Michigan
}

Received December 28, 1989; revised February 20, 1990

\begin{abstract}
A NotI linking library constructed from flow-sorted human chromosome 17 material was screened to aid in construction of a long-range restriction map of the Miller-Dieker chromosome region (MDCR) in 17p13.3. A total of 66 clones were mapped to one of eight regions of chromosome 17 using a somatic cell hybrid panel, and 44/66 (67\%) of these clones crosshybridized to rodent DNA on Southern blots. Of these, 24 clones were tested and all mapped to mouse chromosome 11, the homolog of human chromosome 17. Four linking clones mapped to $17 \mathrm{p} 13.3$ and were used for pulsed-field gel electrophoresis studies along with six other anonymous probes previously mapped to this region. Clone L132 was found to be deleted in all Miller-Dieker patients tested $(n=15)$ and therefore lies within the critical region for this disorder. It detects two NotI fragments (180 and $320 \mathrm{~kb})$, one of which (320 kb) was shared by YNZ22 and YNH37, two probes previously shown to be co-deleted in all patients with the Miller-Dieker syndrome (MDS). These results indicate that all MDS patients share a minimum deletion region of $>370 \mathrm{~kb}$. Two other NotI clones, L53 and L125, mapped telomeric to the MDS critical region and share a 600-kb MuI fragment with each other and with YNZ22/YNH37. This provides a 930-kb MluI map that encompasses the distal boundary of the MDS critical region but does not include the proximal boundary. A total of over $2 \mathrm{Mbp}$ is represented in the $M l u I$ fragments by probes in subband p13.3, a cytogenetic region estimated to be 3-4 Mbp. (c) 1990 Academic Press, Inc.
\end{abstract}

\section{INTRODUCTION}

The Miller-Dieker syndrome (MDS), comprising a severe neuronal migration defect affecting the cerebral

\footnotetext{
${ }^{1}$ To whom correspondence and reprint requests should be addressed.
}

cortex and characteristic facial dysmorphology (reviewed in Dobyns, 1989), is caused by a cytogenetically visible or submicroscopic deletion of chromosome 17, band p13.3 (Ledbetter et al., 1989). Two highly polymorphic VNTR (variable number of tandem repeat; Nakamura et al., 1987) markers, YNZ22 and YNH37, are consistently deleted in all MDS patients tested. It was previously shown that these two independently isolated clones are within $15 \mathrm{~kb}$ of each other, suggesting that the MDS critical region may be quite small (Ledbetter et al., 1989). However, these markers were not physically linked to other probes in $17 \mathrm{p} 13.3$, preventing an accurate estimate of the size of the deletion region.

Genomic clones that contain a rare-cutting restriction site, called linking clones, are particularly useful for pulsed-field gel analysis as they detect two adjacent fragments when genomic DNA is digested with that enzyme (Smith et al., 1987). In addition, linking clones are valuable because a high percentage will identify $\mathrm{CpG}$ islands at the $5^{\prime}$ region of transcribed genes. Wallace et al. (1989) have recently described the construction of a NotI linking library directly from flow-sorted human chromosome 17 material in a $\lambda \mathrm{Ch} 3 \mathrm{~A}$ derivative containing a Not I cloning site. Approximately $80 \%$ of the clones (average insert size $5.5 \mathrm{~kb}$ ) were confirmed to be on chromosome 17 and one clone was characterized in detail to demonstrate that it was an authentic linking clone. This library has also been subsequently used to isolate a linking clone adjacent to the NF1 gene on 17q11.2 (Fountain et al., 1989).

We screened this library to identify NotI linking clones in $17 \mathrm{p} 13.3$ to further characterize the MDS critical region and to develop a long-range restriction map for this chromosome region. Other linking clones were localized to one of eight regions of chromosome 17 and will be useful in the construction of a long-range map for the entire chromosome. 


\section{MATERIALS AND METHODS}

\section{Somatic Cell Hybrid Mapping Panel}

A collection of somatic cell hybrids containing translocations or deletions of chromosome 17 isolated in mouse $\mathrm{TK}^{-}$or Chinese hamster backgrounds has been previously described (vanTuinen et al., 1987, 1988; Ledbetter et al., 1989). To map conserved sequences in mouse, a rat-mouse somatic cell hybrid, $F(11) \mathrm{J}$, containing mouse chromosome 11 as its only mouse DNA was used (Killary and Fournier, 1984).

\section{Screening the Chromosome 17 NotI Linking Library}

The construction and characterization of the library have been previously described (Wallace et al., 1989). Briefly, DNA was prepared from flow-sorted chromosome 17 material and digested to completion with $B g l$ III. It was then ligated at low concentration to promote circularization in the presence of an excess of BamHIended suppressor tRNA genes (supF). The ligated DNA was precipitated and digested with NotI, followed by a final ligation into a bacteriophage $\lambda \mathrm{Ch} 3 \mathrm{~A}$ vector containing a NotI cloning site. The amplified library was plated at $\sim 100$ plaques per $100-\mathrm{mm}$ plate on the sup $^{-}$ Escherichia coli strain MC1061 to select for supF-containing phage. The original characterization of the library demonstrated that a high percentage of clones did not contain genomic DNA, presumably due to nonhomologous ligation of BamHI ends to NotI ends, and it was therefore necessary to screen the library with total human DNA. DNA from positive plaques was isolated from a small-scale liquid culture and digested with NotI to release the insert. The digested DNA was run on a $1 \%$ low-melting-temperature agarose gel and the insert excised for use as probe.

\section{Additional Probes}

pYNZ22 (D17S5), pYNH37 (D17S28), p144D6 (D17S34), EW506 (D17S126), and EW508 (D17S128) are anonymous polymorphic markers previously mapped to $17 \mathrm{p} 13.3$ (Ledbetter et al., 1989). c13A is a 48-kb cosmid that contains the YNZ22 sequence. Cosmid P13 was isolated from a human-mouse hybrid that contains chromosome 17 as its only human material and maps to the MDS critical region (Ledbetter et al., 1989).

Plasmid, cosmid, and phage DNA was isolated by routine methods and labeled with ${ }^{32} \mathrm{P}$ by the random primer method. Hybridizations for conventional Southern blots and pulsed-field blots were carried out in $1 M \mathrm{NaCl}, 10 \%$ dextran sulfate, $1 \% \mathrm{SDS}$, and 500 $\mu \mathrm{g} / \mathrm{ml}$ human placental DNA to compete out the repetitive portion of the probes. The filters were prehybridized for 4-16 h. The probe was boiled for $5 \mathrm{~min}$ and then preannealed at the same placental DNA concentration at $65^{\circ} \mathrm{C}$ for $2 \mathrm{~h}$ before addition to the filters. It was necessary to preassociate both the filter and the probe to allow the use of whole cosmids and the repetitive NotI linking clones on PFGE filters. Hybridization was carried out at $65^{\circ} \mathrm{C}$ for $12-16 \mathrm{~h}$ using 1 $\times 10^{6} \mathrm{cpm} / \mathrm{ml}$ hybridization solution. Filters were washed for $30 \mathrm{~min}$ each at $65^{\circ} \mathrm{C}$ in $2 \times \mathrm{SSC} / 0.1 \% \mathrm{SDS}$ and $1 \times \mathrm{SSC} / 0.1 \%$ SDS and then exposed to Kodak XAR film with an intensifying screen for $24-48 \mathrm{~h}$.

\section{Conventional Southern Blot Analysis}

DNA from lymphoblast and somatic cell hybrids was isolated by routine methods and digested with restriction endonucleases ( 4 units/ $\mu \mathrm{g}$ of DNA) as suggested by the supplier (Boehringer Mannheim). Agarose gel electrophoresis and DNA transfer were performed as described (vanTuinen et al., 1987).

\section{Pulsed-Field Gel Electrophoresis}

High-molecular-weight DNA from lymphoblast lines of normal individuals was isolated in agarose plugs (Schwartz and Cantor, 1984; van Ommen and Verkerk, 1986) and digested with 20-40 units of enzyme as recommended by the supplier. Saccharomyces cerevisiae chromosomes and bacteriophage $\lambda$ DNA concatemers were used as high-molecular-weight size markers. BamHI/EcoRI-digested adenovirus 2 DNA (IBI) was used for lower range molecular weight markers.

The LKB Pulsaphor system was used following the manufacturer's recommendations for voltage and pulse times. The conditions for each gel are given in the figure legends. Transfer of the gel was accomplished as previously described (Ledbetter et al., 1989).

\section{RESULTS AND DISCUSSION}

\section{Isolation and Mapping of NotI Linking Clones on Chromosome 17}

A total of 112 clones were isolated and hybridized to the somatic cell hybrid mapping panel. Of these, 94 clones provided a clear hybridization signal that allowed an unambiguous map assignment. Eighty clones showed positive hybridization to a hybrid (MH22-6) containing chromosome 17 as its only human DNA, indicating a library purity of $85 \%$ consistent with previous results (Wallace et al., 1989). Fourteen clones appeared to be duplicate ascertainments, in that two clones mapping to the same interval showed identical insert sizes and identical hybridization patterns on Southern blots. Thus, a total of 66 different clones that mapped to chromosome 17 were identified.

Human chromosome 17 represents approximately $3 \%$ of the genome (90-100 Mbp). Since the number of 
unmethylated NotI sites on chromosome 17 is perhaps 90-200 (Wallace et al., 1989), these 66 clones should represent approximately $\frac{1}{3}$ to $\frac{2}{3}$ of the potential $\mathrm{CpG}$ related NotI sites for this chromosome. The clones were regionally assigned to one of eight intervals on chromosome 17, as shown in Fig. 1. Most of the clones lie within four intervals on the long arm, with 7 clones mapping to the short arm. There is an apparent underrepresentation of clones in the proximal short arm.

The map position of the four linking clones in p13.3 (distal to the breakpoint in hybrid MH74) was further refined using a high-resolution mapping panel of the MDS region which contains four additional deletions representing five breakpoints (Fig. 2). L66 was found to be proximal to probes 506 and 508 on the centromeric side of the critical region and was not characterized further. L132 was found to be deleted in all MDS patients and therefore falls within the critical region for this disorder. L53 and L125 were found to be distal to the critical region but proximal to the telomeric marker 144D6. Since these two markers fell into the same deletion interval, their relative order on the chromosome could not be determined.

\section{Mapping to Mouse Chromosome 11}

Wallace et al. (1989) previously noted that a high percentage of NotI linking clones $(6 / 16)$ cross-hybridized to DNA of other species. This is consistent with the prediction that linking clones will frequently identify $\mathrm{CpG}$ islands at the $5^{\prime}$ region of transcribed genes

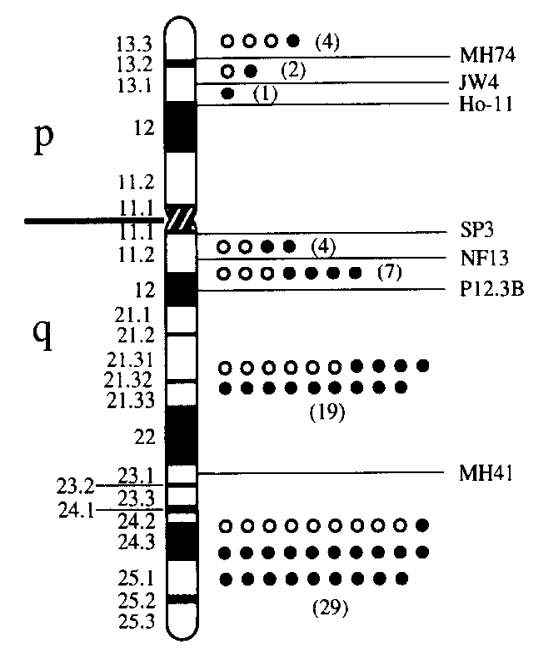

FIG. 1. Localization of 66 NotI linking clones to eight regions of chromosome 17 as determined by hybridization to a panel of somatic cell hybrids containing translocations or deletions of chromosome 17 (hybrids MH74, JW4, SP3, P12.3B, and MH41 are described in Ref. (12); hybrid Ho-11 is described in Ref. (11); hybrid NF13 is described in Ref. (5)). Open circles represent clones that gave clear positive signals to mouse chromosome 11 in hybrid $\mathrm{F}(11) \mathrm{J}$. Numbers in parentheses represent the total number of NotI clones mapped to each interval.

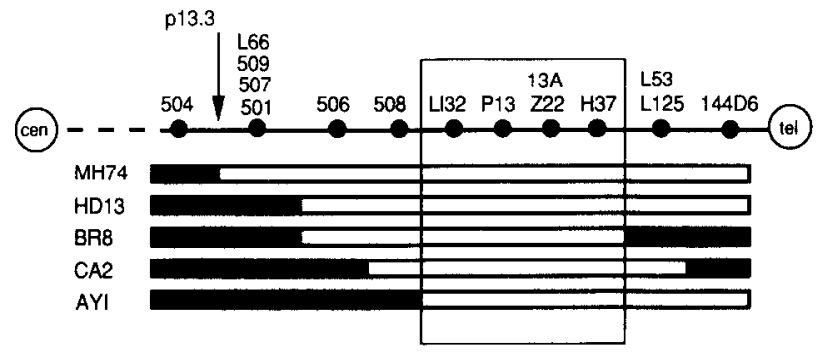

FIG. 2. Fourteen anonymous DNA markers including 4 NotI linking clones are ordered within band 17 p13.3 on the basis of their presence or absence in hybrids containing deletion chromosomes 17 from five MDS patients (5). Probes are ordered from centromere (cen) to telomere (tel). A cytogenetically visible breakpoint at p13.3 is indicated by an arrow. Bars below the map indicate the results of hybridization of the 14 probes, with hybrid designation to the left. Filled bars represent positive hybridization (not deleted) and open bars represent negative hybridization (deleted). The smallest region of overlap among the seven deletions is indicated by the box and includes probe L132, cosmid P13, cosmid 13A (which contains YNZ22), YNZ22, and YNH37. The order of probes within this box was determined by subsequent pulsed-field gel experiments.

(Smith et al., 1987) and with the calculation by Lindsay and Bird (1987) that $89 \%$ of all NotI sites will be found in $\mathrm{CpG}$ islands. In the current study, 44 of 66 linking clones $(67 \%)$ showed cross-hybridization to mouse DNA at normal stringency $(1 \times \mathrm{SSC} / 0.1 \%$ SDS at $65^{\circ} \mathrm{C}$ ) and therefore potentially identify a transcribed sequence.

Conservation of these sequences in mouse permits the localization of these clones to a specific mouse chromosome by physical or genetic mapping methods. It has previously been shown that there is extensive conservation between human chromosome 17 and mouse chromosome 11. In fact, every gene or conserved sequence previously mapped to human 17 has been found to localize on mouse chromosome 11 (Buchberg et al., 1989).

To test whether the linking clones were also on mouse chromosome 11,24 clones were hybridized to the rat-mouse somatic cell hybrid containing mouse chromosome 11 as its only mouse DNA (Killary and Fournier, 1984). All 24 were positive for a mouse-specific band, thereby confirming their assignment to mouse chromosome 11 . The distribution of the 24 clones tested is indicated by the open circles in Fig. 1. These markers should be useful for more refined genetic mapping of mouse chromosome 11 using an interspecific backcross strategy.

The most distal $17 \mathrm{p}$ markers previously shown to map to mouse chromosome 11 are YNZ22 and YNH37, which lie within the MDS critical region (Ledbetter et $a l ., 1989$ ). Three linking clones in 17p13.3 (L132, L53, and L125) cross-hybridized to mouse and mapped to mouse chromosome 11 . Clones L53 and L125 lie distal to the MDS critical region (Fig. 2), and their assign- 
ment to mouse chromosome 11 further extends the homology toward the 17p telomere. In distal 17q (q23qter), 9/9 NotI linking clones map to mouse chromosome 11 (Fig. 1). This suggests the homology with mouse 11 may span the entire human chromosome 17 . Identification of conserved sequences adjacent to the telomeres of $17 p$ and $17 q$ will be necessary to test this possibility more rigorously.

\section{Long-Range Restriction Map of 17p13.3}

A total of 10 different probes that map within the single subband 17p13.3 (Fig. 2) were used for pulsedfield gel experiments. Complete digest fragment sizes for each probe with seven different rare-cutting enzymes are shown in Table 1. Results for the two VNTR clones within the critical region, YNZ22 and YNH37, were previously reported (Ledbetter et al., 1989) and indicate that these two independently isolated probes are very close to each other, detecting the same $29-\mathrm{kb}$ $S f i$ fragment. The NotI and BssHII fragment sizes for YNZ22 were extremely small, indicating that this probe probably encompasses a CpG island. Cosmid clone 13A, which contains the YNZ22 sequence, was also used on pulsed-field gels and identified a number of additional restriction fragments not detected by YNZ22. This included a $29-\mathrm{kb}$ BssHII fragment shared by YNH37, as well as additional $N o t I, S f I$, and $M l u I$ fragments. Thus, cosmid 13A served as a chromosome walk across a number of rare restriction sites in the immediate vicinity of YNZ22.

Cosmid P13, an independently isolated clone that does not contain YNZ22 or YNH37 sequences, detected many fragments in common with cosmid 13A. The smallest of the common fragments was a $42-\mathrm{kb} S f \mathrm{I}$ fragment, indicating that the two cosmid clones were in very close proximity. Restriction mapping and hybridization studies showed that the two cosmids overlapped by $8 \mathrm{~kb}$ (not shown).

L132, found to map within the MDS critical region, detects very small fragments with $B s s \mathrm{HII}$ (5 and 48 $\mathrm{kb})$ and $S f I$ ( 6 and $15 \mathrm{~kb}$ ), consistent with the presence of a CpG island. It detects two NotI fragments (Fig. 3 ), as expected for an authentic linking clone. One of these fragments $(320 \mathrm{~kb})$ is also detected by cosmids $\mathrm{P} 13$ and 13A, indicating that the distance between L132 and 13A (YNZ22) is $320 \mathrm{~kb}$. The same three probes also identify an identical $M l u I$ fragment of approximately $330 \mathrm{~kb}$. The similarity in size of the NotI and MluI fragments is consistent with the presence of two CpG islands separated by approximately $320 \mathrm{~kb}$.

The identification of a new probe consistently deleted in MDS patients and $320 \mathrm{~kb}$ away from YNZ22

TABLE 1

Pulsed-Field Gel Fragment Sizes (Complete Digests) ${ }^{n}$

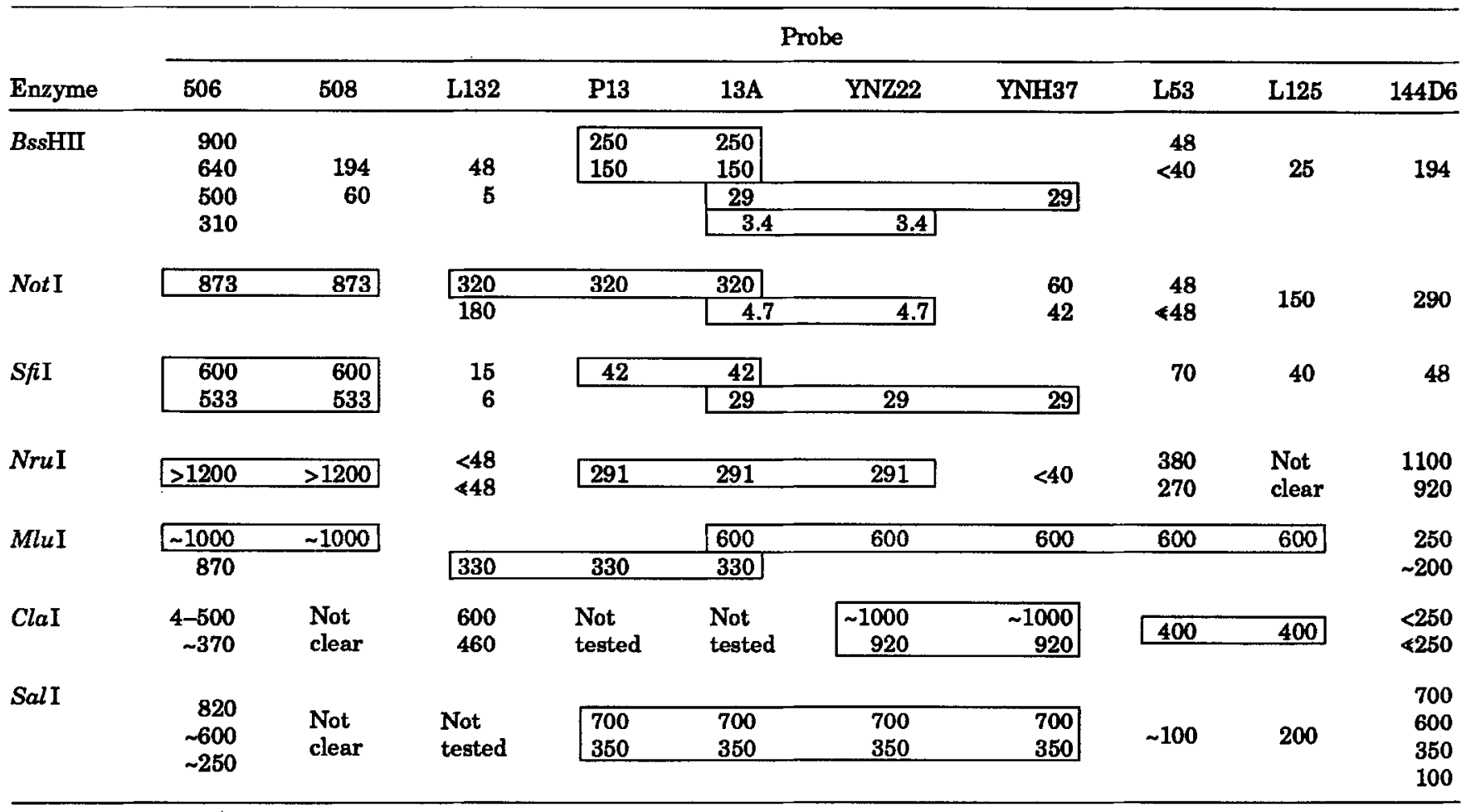

\footnotetext{
${ }^{\circ}$ Fragment sizes are given in $\mathrm{kb}$. Identical fragments detected by multiple probes are enclosed in boxes.
} 


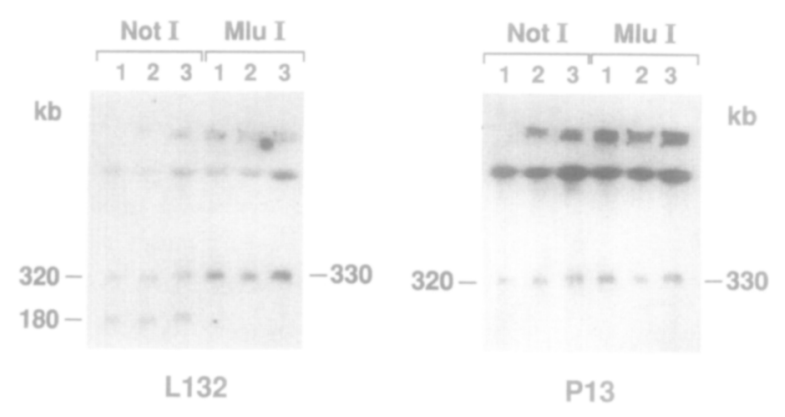

FIG. 3. Pulsed-field gel analysis using probe L132 (left) and cosmid P13 (right). DNA from lymphoblastoid cell lines of three unrelated individuals was digested with 20 units of NotI or 40 units of $M l u \mathrm{I}$ for $4 \mathrm{~h}$ at $37^{\circ} \mathrm{C}$. A $1 \%$ gel was run in $60 \mathrm{mM}$ Tris $/ 60 \mathrm{mM}$ boric acid/1 $\mathrm{mM}$ EDTA using a $45-\mathrm{s}$ pulse for $20 \mathrm{~h}$ to resolve fragments in the size range $40-600 \mathrm{~kb}$. L132 detected two NotI fragments, 320 and $180 \mathrm{~kb}$, and a $330-\mathrm{kb}$ Mlul fragment. The filter was stripped and rehybridized to cosmid P13, which detected the same $320-\mathrm{kb}$ NotI fragment and 330-kb MluI fragment.

greatly increases the minimum region of overlap present in these patients. Previous data had shown three overlapping cosmid clones spanning $100 \mathrm{~kb}$ deleted in $15 / 15$ patients. The present results add another 300 kb to that estimate, or about $400 \mathrm{~kb}$ total. One possible interpretation of these data is that disruption of at least two genes is necessary to produce the MDS phenotype, and their separation by several hundred kilobases in the genome requires large molecular deletions as the causal mechanism.

Probes L53 and L125 map distal to the critical region but proximal to the telomeric marker 144D6. L53 detects two small NotI fragments of about 48 and $\ll 48$ kb, while L125 identifies a single NotI fragment of 150 kb (detection of only one NotI fragment could result from two co-migrating fragments, one fragment being too small for detection under the conditions used, or the presence of a very small or repetitive sequence on one side of the NotI site that fails to hybridize adequately). Both probes detect small fragment sizes with most rare-cutting enzymes. The smallest common fragment is a $400-\mathrm{kb} C l a \mathrm{I}$ fragment, indicating that the two probes are within $400 \mathrm{~kb}$ of each other. Neither of the two probes shares any fragments in common with the telomeric marker 144D6.

$M l u I$ gave the largest fragment size for these two probes, detecting a 600 -kb fragment with both probes that is identical to the $600-\mathrm{kb}$ fragment detected by YNH37, YNZ22, and cosmid 13A (Fig. 4). This result establishes a continuous $930-\mathrm{kb}$ MluI map connecting the MDS critical region with telomeric probes outside the deletion region (Fig. 5). It also suggests the order cen-L132-YNZ22-YNH37-(L53， L125)-144D6-tel. The order for YNZ22 and YNH37 relative to 144D6 obtained here is different from the published genetic map (Nakamura et al., 1987). However, given the ex-

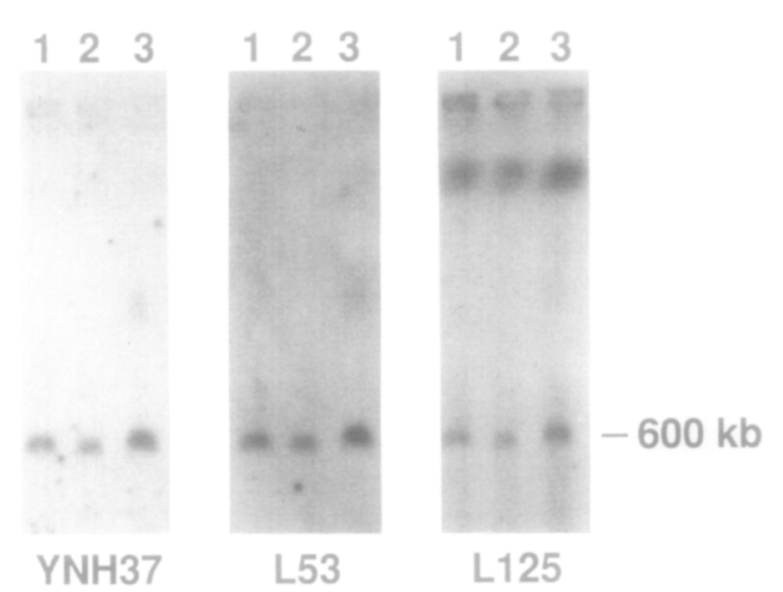

FIG. 4. Pulsed-field analysis with probes YNH37, L53, and L125. DNA from lymphoblastoid cell lines of three unrelated individuals was digested with 40 units of $M l u I$ for $4 \mathrm{~h}$ at $37^{\circ} \mathrm{C}$. A $1 \%$ gel was run in $60 \mathrm{~m} M$ Tris $/ 60 \mathrm{~m} M$ boric acid/1 $\mathrm{mM}$ EDTA using a 90-s pulse time for $15 \mathrm{~h}$ followed by a 125-s pulse time for $9 \mathrm{~h}$ to resolve fragments in the size range $40-1000 \mathrm{~kb}$. The filter was hybridized sequentially to L125, L53, and then YNH37. All three probes detected an identical 600-kb MluI fragment (hybridization to the compression zone seen with L125 in this figure was present for all three probes in two other pulsed-field analyses).

tremely close physical proximity of the two probes, it is not surprising that linkage is not able to resolve their order.

The proximal probes 506 and 508 have a number of relatively large restriction fragments in common, the smallest being a 533-kb $S f$ i I fragment. None of the enzymes tested showed common fragments between these probes and L132 or other markers within the MDS critical region, leaving a gap in the pulsed-field map on the proximal side.

The present physical mapping data demonstrate that all Miller-Dieker syndrome patients are deleted for a region of at least $370 \mathrm{~kb}$. A continuous $930-\mathrm{kb} \mathrm{MluI}$ map that encompasses the telomeric boundary but not the centromeric boundary has been constructed in the MDS critical region. MluI fragments totaling over 2 Mbp have been identified by probes within subband $17 \mathrm{p} 13.3$, a cytogenetic region estimated to be no more

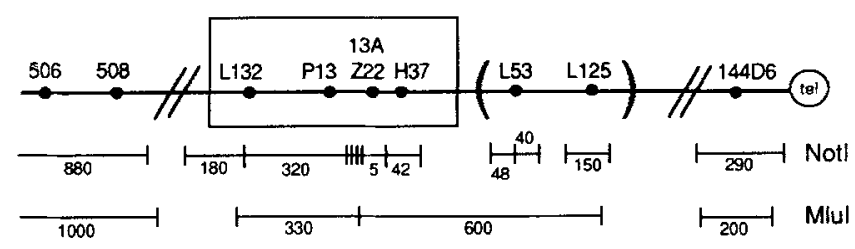

FIG. 5. Summary of NotI and MluI map around the MDS critical region (numbers indicate sizes of fragments in $\mathrm{kb}$ ). Cosmid $13 \mathrm{~A} \mathrm{con-}$ tains the YNZ22 sequence. The order of L53 and L,125 has not been established conclusively by physical mapping, as indicated by the parentheses. 
than 3-4 Mbp. Isolation of additional linking clones or other probes in this region should allow identification of the proximal boundary of the MDS critical region as well as completion of the long-range restriction map for the entire subband.

\section{ACKNOWLEDGMENTS}

The authors thank Doreen Osterholm, Kerry George, and Elizabeth Lovell for excellent technical assistance, Drs. Yusuke Nakamura and David Barker for providing chromosome 17 probes, and Dr. Ann Killary for hybrid $F(11) J$. This work was supported by grants from the National Institutes of Health (HD20619 to D.H.L. and GM34960, NS23427, and NS23410 to F.S.C.) and from the Howard Hughes Medical Institute (F.S.C.).

\section{REFERENCES}

1. Buchberg, A. M., Brownell, E., Nagata, S., Jenkins, N. A., AND COPELAND, N. G. (1989). A comprehensive genetic map of murine chromosome 11 reveals extensive linkage conservation between mouse and human. Genetics 122: 153-161.

2. DoBYNS, W. B. (1989). The neurogenetics of lissencephaly. Neurol. Clinics 7: 89-105.

3. Fountain, J. F., Wallace, M. R., BRuce, M. A., SEItFNGer, B. R., MENON, A. G., GuSella, J. F., MiChELS, V. V., SCHMIDT, M. A., Dewald, G. W., AND Collins, F. S. (1989). Physical mapping of a translocation breakpoint in neurofibromatosis. Science 244: 1085-1087.

4. KILLARY, A. M., AND FourNIER, R. E. (1984). A genetic analysis of extinction: Trans-dominant loci regulate expression of liverspecific traits in hepatoma hybrid cells. Cell 38: 523-534.

5. LEDBETTER, D. H., LEDBETTER, S. A., VANTUINEN, P., SUMMERS, K. M., ROBINSON, T. J., NAKAMURA, Y., WolfF, R., White, R., BARKER, D. F., WALlaCE, M. R., Collins, F. S., AND DOBYNS, W. B. (1989). Molecular dissection of a contiguous gene syndrome: Frequent submicroscopic deletions, evolutionarily conserved sequences, and a hypomethylated "island" in the Miller-Dieker chromosome region. Proc. Natl. Acad. Sci. USA 86: $5136-5140$.

6. LINDSAY, S., AND BIRD, A. P. (1987). Use of restriction enzymes to detect potential gene sequences in mammalian DNA. Nature (London) 327: 336-338.

7. Nakamura, Y., LePPert, M., O'CONNEll, P., WolfF, R., Holm, T., Culver, M., Martin, C., Fujimoto, E., Hof, M., KUMLIN, E., AND WHITE, R. (1987). Variable number of tandem repeat (VNTR) markers for human gene mapping. Science 23: 1616-1622.

8. SCHWARTZ, D. C., AND CANTOR, C. R. (1984). Separation of yeast chromosome-sized DNAs by pulsed field gradient gel electrophoresis. Cell 37: 67-75.

9. Smith, C. L., Lawrance, S. K., Gillespie, G. A., Cantor, C. R., Weissman, S. M., AND Collins, F. S. (1987). Mapping and cloning macro-regions of mammalian genomes. In "Methods in Enzymology" (M. Gottesman, Ed.), Vol. 151, pp. 461489, Academic Press, San Diego.

10. VAN OMMEN, G. J. B., AND VERKERK, J. M. H. (1986). Restriction analysis of chromosomal DNA in a size range up to two million base pairs by pulsed field gradient electrophoresis. In "Human Genetic Diseases: A Practical Approach" (K. E. Davies, Ed.), pp. 113-117, IRL Press, Oxford.

11. vanTuinen, P., Dobyns, W. B., Rich, D. C., Summers, K. M., ROBINSON, T. J., NAKAMURA, Y., AND LEDBETTER, D. H. (1988). Molecular detection of microscopic and submicroscopic deletions associated with Miller-Dieker syndrome. Amer. J. Hum. Genet. 43: 587-596.

12. VANTUinen, P., RiCH, D. C., Summers, K. M., AND LeDBetTeR, D. H. (1987). Regional mapping panel for human chromosome 17: Application to neurofibromatosis type 1. Genomics 1: $374-$ 381.

13. Wallace, M. R., Fountain, J. W., Brereton, A. M., AND Collins, F. S. (1989). Direct construction of a chromosomespecific NotI linking library from flow-sorted chromosomes. Nucleic Acids Res. 17: 1665-1677. 